\title{
Remote Sensing Observations of the Winter Yellow Sea Warm Current Invasion into the Bohai Sea, China
}

\author{
Jie Guo, ${ }^{1}$ Hua Zhang, ${ }^{1}$ Tingwei Cui, ${ }^{2}$ Yijun He, ${ }^{3}$ Jie Zhang, ${ }^{2}$ Kai Guo, ${ }^{1}$ \\ Chawei Hou, ${ }^{4}$ and Rongjie Liu ${ }^{2}$ \\ ${ }^{1}$ Shandong Provincial Key Laboratory of Coastal Zone Environmental Processes, Yantai Institute of Coastal Zone Research, \\ Chinese Academy of Sciences, No. 17 Chunhui Road, Laishan, Yantai 264003, China \\ ${ }^{2}$ First Institute of Oceanography, SOA, No. 6 Xianxialing Road, Qingdao 266061, China \\ ${ }^{3}$ School of Marine Sciences, Nanjing University of Information Science and Technology, No. 219 Ningliu Road, \\ Nanjing, Jiangsu 210044, China \\ ${ }^{4}$ Yantai Marine Environmental Monitoring Central Station, SOA, No. 16 Xihaiyang Beijie Road, Yantai 264006, China \\ Correspondence should be addressed to Jie Guo; jguo@yic.ac.cn
}

Received 6 August 2015; Revised 9 October 2015; Accepted 12 October 2015

Academic Editor: James Cleverly

Copyright (C) 2016 Jie Guo et al. This is an open access article distributed under the Creative Commons Attribution License, which permits unrestricted use, distribution, and reproduction in any medium, provided the original work is properly cited.

Using ASCAT, QuikSCAT, and MODIS data, we analyzed the sea surface wind field, temperature, salinity, and chlorophyll concentrations in the mixed zone between the Bohai Sea and Yellow Sea in the winter (the period of winter 2013 included December 2013 and January-February 2014) from 2002 to 2013. We found that the intrusion of the Yellow Sea Warm Current into the Bohai Sea occurred three times in the winters of 2007 (strongest), 2004, and 2013 (weakest) during this 12-year period. We present detailed validation of the intrusion in 2013. This study shows that the intrusion of the Yellow Sea Warm Current into the Bohai Sea occurred when the wind speed, sea surface temperature, and salinity were above (or close to) the multiyear average and the chlorophyll concentration was less than the multiyear average.

\section{Introduction}

The Yellow Sea Warm Current (YSWC) is a branch of the Tsushima Current, which both branch from the Kuroshio Current [1-3]. The YSWC originates in the area northeast of the East China Sea and south of the Jeju Island of Korea. It is the only source of sea water from the open sea entering the Yellow Sea and is characterized by high temperature, high salinity (SAL), and low dissolved oxygen content [4].

There are many important issues surrounding the YSWC. For example, existing high-resolution numerical simulations suggest that the path and intensity of the YSWC are altered by the wind [5-9]. Yuan et al. [8] showed that winter northerly winds could drive the YSWC north to flow across the Yellow Sea trough. Tang et al. [7] showed that the path of the YSWC had clear seasonal and interannual variations. Numerical calculations showed that the variations were closely related to the strength of the northerly wind. Model simulation by Song et al. [4] revealed clear 5-year variability in the YSWC and found a south-north shifting that correlated with the zonal and meridional wind variability. In a strong wind situation, the YSWC intrudes further into the northern Yellow Sea. Using model simulation, Miu and Liu [10] found a northwestward flow along the northern Yellow Sea trough and assumed that it was the YSWC. The flow moves along the Yellow Sea trough against the wind, moving up from the deep area at the north of the Bohai Strait and extending to the central Bohai Sea. Shen and Mao [11] found that sea surface SAL of the eastern Bohai Sea reached a maximum in February and March every year.

From the review above, we found that it is not conclusive how and when the YSWC path enters the Bohai Strait. Furthermore, it is not clear whether the YSWC forms a persistent current into the Bohai Strait.

The Bohai Sea is an inland sea of China, with an average depth of about $18 \mathrm{~m}$. The sea is rich in fishery resources, with busy industrial activities for ocean-shipping, petrochemical, and salt products [12]. The Bohai Strait is the only channel 
TABLE 1: Remote sensing data used in this study.

\begin{tabular}{lccccc}
\hline Source & \multirow{2}{*}{ Resolution } & Time & Purpose & $\begin{array}{c}\text { Temporal resolution } \\
\text { day }\end{array}$ & Products \\
\hline ASCAT_L3 & $25 \mathrm{~km}$ & $2007-2013$ & Wind field & $2 \sim 3$ & C band \\
QuikSCAT_V4 & $25 \mathrm{~km}$ & $2002-2006$ & Wind field & $1 \sim 2$ & Ku band \\
MODIS_L3 & $9 \mathrm{~km}$ & $2002-2013$ & SST & $1 \sim 2$ & $3.66-3.84 \mu \mathrm{m}$ \\
MODIS_L3 & $9 \mathrm{~km}$ & $2002-2013$ & CHL & $1 \sim 2$ & $405-420 \mu \mathrm{m}$ \\
MODIS_L3 & $9 \mathrm{~km}$ & $2002-2013$ & SAL & $1 \sim 2$ & $\begin{array}{c}\text { Monthly climatology remote sensing } \\
\text { reflectance at } 488 \mathrm{~nm}, 555 \mathrm{~nm} \text {, and } \\
\end{array}$ \\
& & & & $667 \mathrm{~nm}$ \\
\hline
\end{tabular}

connecting the Bohai Sea to the open ocean, that is, the Yellow Sea. The Yellow Sea is a semiclosed shelf shallow sea (depth $70-100 \mathrm{~m}$ and average $44 \mathrm{~m}$ ). There is a group of sand ridges located to the north of Bohai Strait [13, 14]. Surface observation data in Bohai Strait are not easily obtained, as waves whipped up by the wind roll turbulently in this area.

With the development of remote sensing technology, modern satellite data are frequently collected over the mixed zone between the Yellow Sea and Bohai Sea (Y-B) and are advantageous in monitoring the evolution of the YSWC path. Based on daily sea surface temperature (SST) of NOAA/ AVHRR $[15,16]$, sea surface height (SSH) from AVISO, and the wind data recorded in the Chengshantou Station of China, Zhao et al. [17] identified two tongue-shaped branches of warm waters associated with the YSWC intrusion. Furthermore, statistical results revealed that these two branches were always present from 1981 to 2010. They found that the SSH was lower in the southern Yellow Sea than in the YSWC in the middle of September and from the end of February to early March. Starting in late March, the SSH was higher in the YSWC than in the southern Yellow Sea. Correlation analysis of the variation of the local SSH of the Yellow Sea indicated that the northwestern and northern branches of the YSWC were driven by relatively local SSH changes, caused by regional winds. They analyzed the characteristics of the YSWC using remote sensing data in combination with observational data; however, there was a lack of conclusive data on the SAL to analyze.

In a different area, Yuan et al. [18] studied the surface Kuroshio path in the Luzon Strait area using satellite ocean color, sea surface temperature, and altimeter data. The results suggested that the dominant path of the surface Kuroshio intrusion in the winter was a direct route from northeast of Luzon to southwest of Taiwan and then westward along the continental slope of the northern South China Sea.

All these issues are related to the YSWC intrusion into the Bohai Strait, which can be investigated using remote sensing ocean color and active microwave data. Many observations have indicated that the Kuroshio loop current is primarily a winter phenomenon and to date its occurrence in summer has not been frequently observed [19-21]. Winter is therefore the best season to observe the YSWC [17]. Further, the development of remote sensing technology provides a great possibility of studying the regional characteristics of the YSWC. Research on the YSWC invasion into the Bohai Sea will significantly affect research on its ecological environment and the survival of fisheries spawning grounds. Its invasion clearly related to climate change.

In this study, we investigated the winter YSWC path in the mixed zone Y-B by remote sensing data based on wind field (atmospheric pressure changes cause sea surface wind field) and SST variations, with factor analyses of SAL, chlorophyll concentration (CHL), northerly wind days, and high wind days. We study that if remote sensing data show the intrusion of YSWC into the Bohai Sea, how to form decision criteria by remote sensing data and how to use the in situ data validate the criterion.

\section{Materials and Methods}

We used remote sensing data from the winter of 2013 as a case study to analyze and validate the in situ and cross section observational data. The sea surface wind field, temperature, SAL, CHL, wind scale, and high wind days were used to analyze characteristics of the mixed zone between the Bohai Sea and Yellow Sea in winters using remote sensing data.

2.1. Data Collection. The primary satellite data (Table 1) used to study the YSWC intrusion into the Bohai Sea in the winter was sea surface wind field data. Data were obtained from ASCAT_L3 daily average data on a global grid of about $25 \mathrm{~km}$ resolution (ftp://ftp.ifremer.fr/ifremer/cersat/products/gridded/MWF/L3/ASCAT/Daily/) and QuikSCAT_V4 daily average data in the Ku band on a global grid of about $25 \mathrm{~km}$ resolution (http://www.remss.com/missions/qscat). To reduce the cloudiness of the MODIS data, the monthly averaged sea surface SST and CHL data from MODIS_L3/Terra at $9 \mathrm{~km}$ resolution were used in this study (http://oceancolor.gsfc.nasa .gov/cgi/l3). The period of winter 2013 included December 2013 and January-February 2014. Scatterometer wind had an accuracy of less than $1 \mathrm{~m} / \mathrm{s}[22,23]$.

2.2. Methods. We computed the monthly average for all parameters. Validation data were from in situ and cross section observational data from ships. The SAL-retrieving algorithm for this study is from Qing et al. [24]. The model was recalibrated based on remote sensing reflectance data derived from MERIS and from in situ SAL data, yielding a root mean square error (RMSE) in modeled SAL of 1.31 psu (relative to in situ data). This recalibrated model was applied to MODIS 


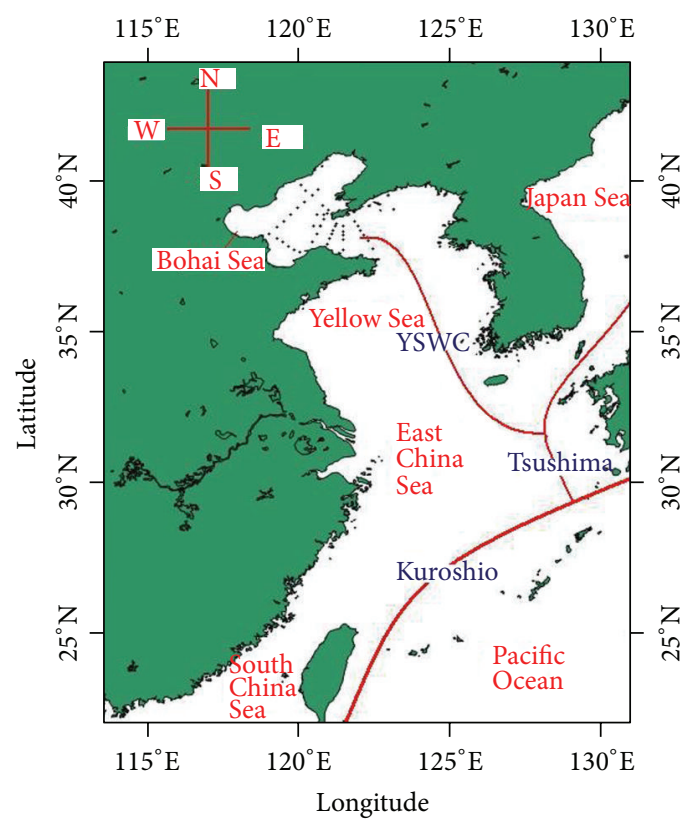

FIGURE 1: Study area (with symbol display area) sketch map.

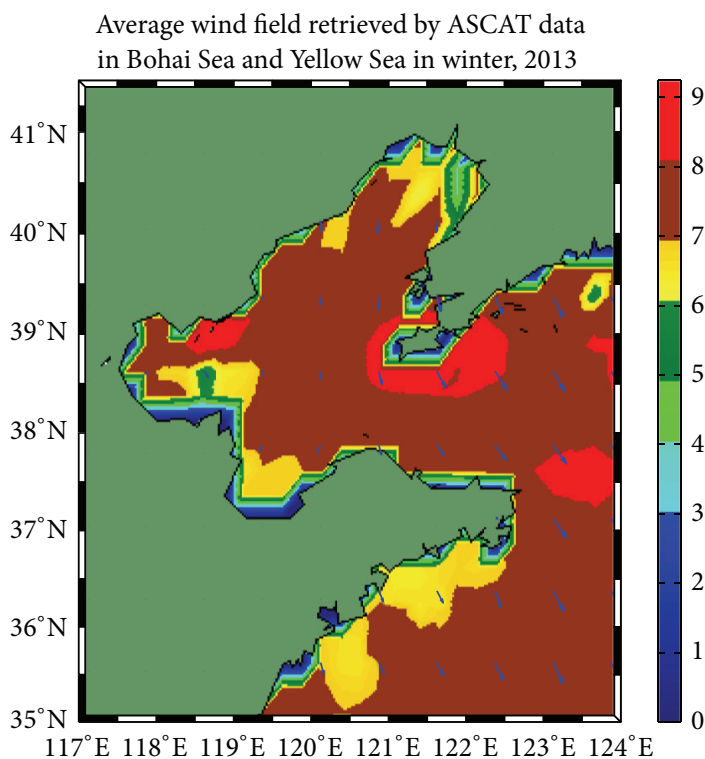

(a)
Average wind field retrieved by Scatterometer data in Bohai Sea and Yellow Sea in winter, 2002-2012

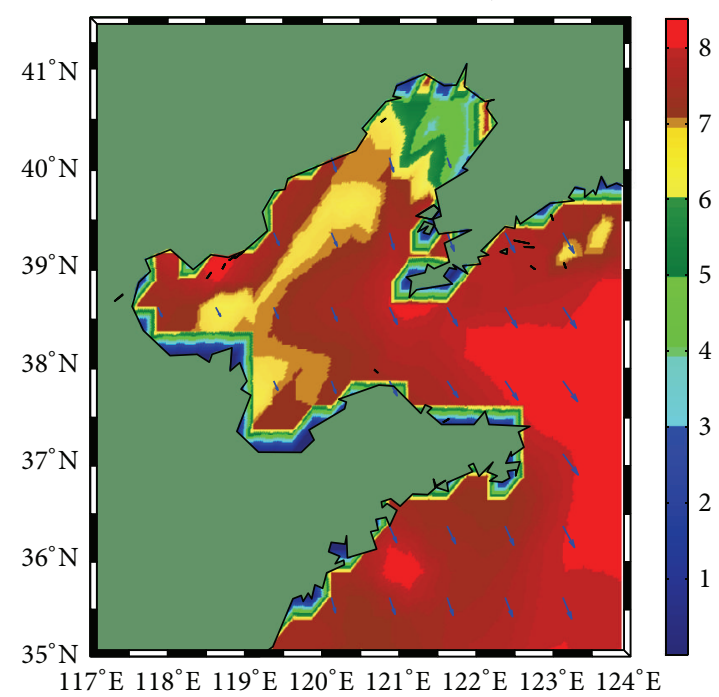

(b)

Figure 2: The average wind field retrieved by Scatterometer data in Y-B in winter 2013 (a) and 2002-2012 (b) (unit: m/s).

data following a linear correction for SAL in the mixed zone Y-B:

$$
\begin{aligned}
\lg (\mathrm{SAL})= & 7.8 \times R_{r s}(488)-11.325 \times R_{r s}(555) \\
& +2.183 \times R_{r s}(667)+1.53
\end{aligned}
$$

With winter remote sensing data from nearly 12 years, from 2002 to 2013, we analyzed the characteristics of the entry of the YSWC into the Bohai Sea, in the study area (Figure 1, spans $37.5-39^{\circ} \mathrm{N} / 120-124^{\circ} \mathrm{E}$ in Y-B to avoid the land).

\section{Results and Discussion}

3.1. Wind Field Inversion of Y-B Mixed Zone from ASCAT Data. Wind field data were obtained from ASCAT_L3 data and displayed in Table 1. There were 90 wind field data points retrieved from ASCAT data, in the mixed zone, Y-B. In winter 2013, the average wind speed was $7.83 \mathrm{~m} / \mathrm{s}$ (Figure 2(a)) compared with the average value of $7.71 \mathrm{~m} / \mathrm{s}$ for $2002-2012$ (Figure 2(b)). The wind speeds (2002-2012) were a fusion of ASCAT (2007-2012) and QuikSCAT (2002-2006) data, through Kriging interpolation in Figure 2(b). In winter 2013, 


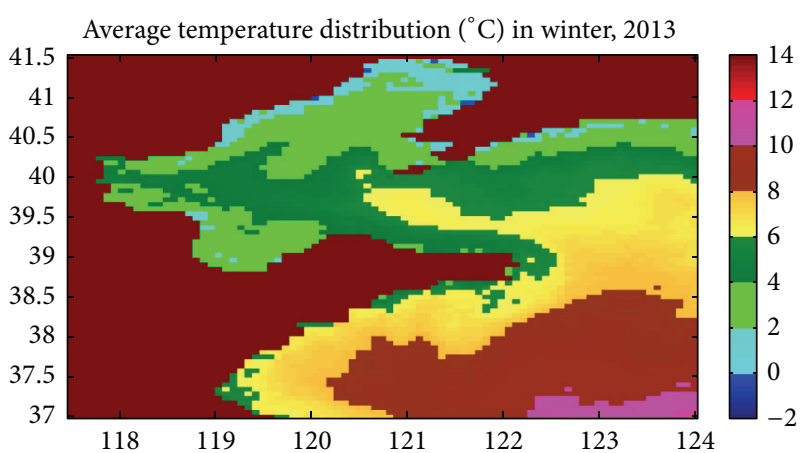

(a)

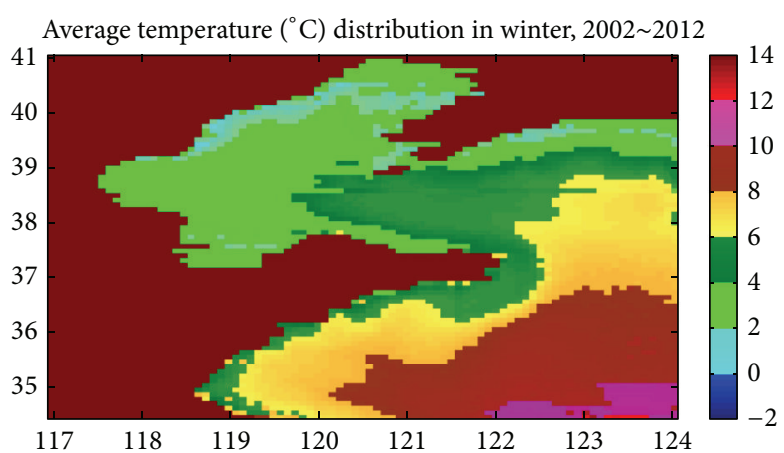

(b)

FIGURE 3: Average SST distribution in winter 2013 (a) and 2002-2012 (b).

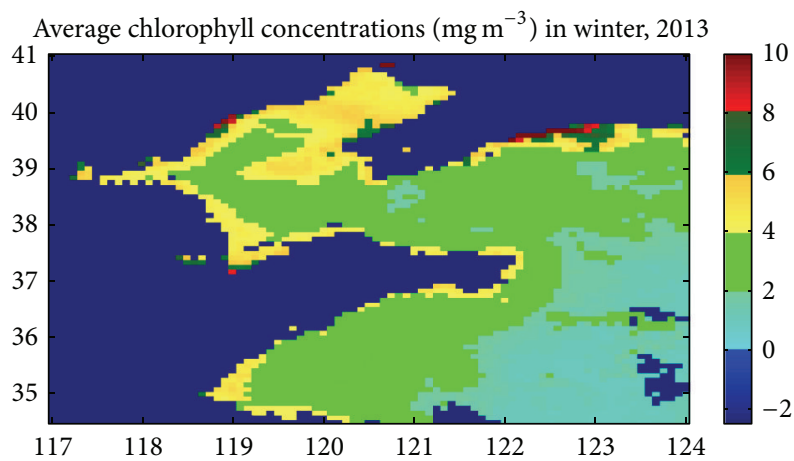

(a)

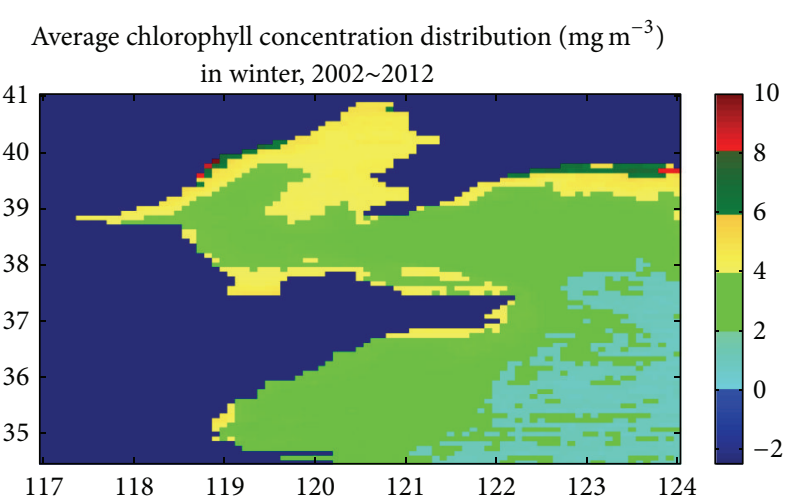

(b)

Figure 4: Average CHL distribution in winter 2013 (a) and 2002-2012 (b).

the numbers of windy days were defined on the Beaufort scale $1-2,2-3,3-4,4-5,5-6$, and 6-7, with $1,12,28,24,19$, and 6 days, respectively (Table 2 ). On the Beaufort scale, a wind with average maximum speed above level $6(\geq 10.8 \mathrm{~m} / \mathrm{s})$ for $10 \mathrm{~min}$ is termed a high wind and above level $8(\geq 17.2 \mathrm{~m} / \mathrm{s})$ is a strong wind [25].

Table 2 shows the number of days with each of the different wind directions: east (E) (occurring in 2 days), south (S), west (W), north (N), NNE, NNW, SSW, SSE, NWW, WSW, ESE, and NEE. We found that northerly winds occurred in 55 days (61\%) in winter 2013.

3.2. SST Inversion Revealed by MODIS Data. The retrieved SST from MODIS_L3 monthly average data in winters of 2013 and 2002-2012 showed that temperature varied from $4^{\circ} \mathrm{C}$ to $8^{\circ} \mathrm{C}$ in the study region. There were 174 SST data points retrieved from MODIS_L3 data in the mixed zone Y-B. The average temperature was $7.23^{\circ} \mathrm{C}$ in winter 2013 (Figure 3(a)), which was higher than the average value of $6.71^{\circ} \mathrm{C}$ (Figure 3(b)) from winter of 2002-2012.

3.3. CHL Inversion from MODIS Data. The CHL distribution retrieved from MODIS_L3 monthly average data in winters of 2013 and 2002-2012 varied from 0 to $4 \mathrm{mg} / \mathrm{m}^{3}$. There were 428 CHL data points retrieved from MODIS_L3 data in the mixed
TABLE 2: Characteristics of wind field at Y-B mixed zone in winter 2013.

\begin{tabular}{lccccc}
\hline $\begin{array}{l}\text { Wind } \\
\text { scale }\end{array}$ & Days (90) & Wind_dir & Days (64) & Wind_dir & Days (26) \\
\hline $1 \sim 2$ & 1 & E & 2 & SSW & 6 \\
$2 \sim 3$ & 12 & S & 5 & SSE & 8 \\
$3 \sim 4$ & 28 & W & 9 & ESE & 3 \\
$4 \sim 5$ & 24 & N & 10 & WSW & 2 \\
$5 \sim 6$ & 19 & NNE & 15 & NWW & 6 \\
$6 \sim 7$ & 6 & NNW & 23 & NEE & 1 \\
\hline
\end{tabular}

zone Y-B. The average CHL in winter 2013 was $3.02 \mathrm{mg} / \mathrm{m}^{3}$ (Figure $4(\mathrm{a})$ ) and $3.06 \mathrm{mg} / \mathrm{m}^{3}$ for 2002-2012 (Figure 4(b)). There was no more variation in CHL in 2013 than in 20022012.

3.4. Salinity Inversion from MODIS. MODIS_L3 observations and inversion SAL from formula (1) showed that the SAL ranged from 31.03 to 32.93 psu in the winter of 2013 (Figure 5(a)). There were $779 \mathrm{SAL}$ data points retrieved from MODIS_L3 data in the mixed zone Y-B. In the study region, the averaged value ranged from 28.97 to $32.82 \mathrm{psu}$ (Figure 5(b)) in 2002-2012. 

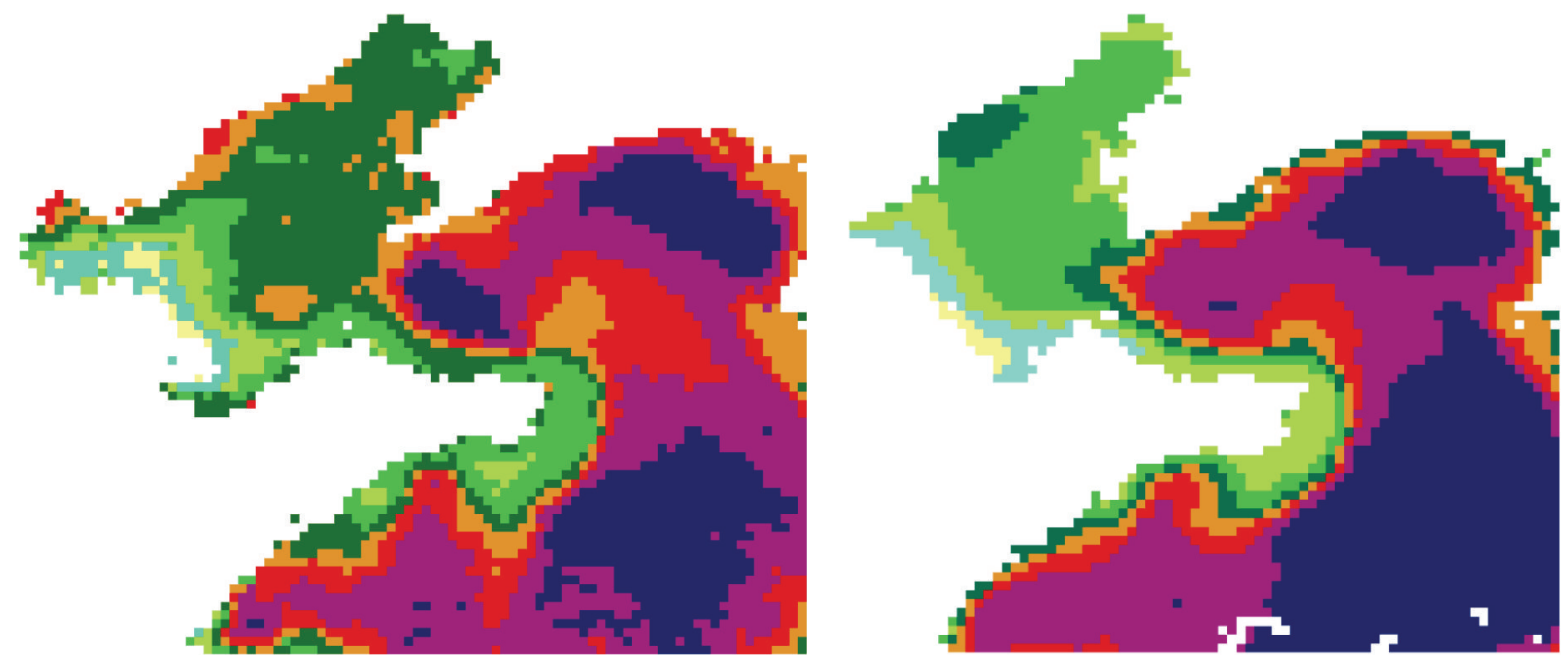

Salinity

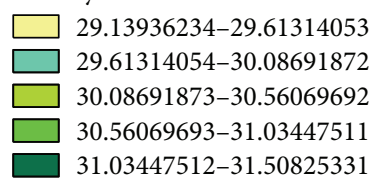

(a)
31.50825332-31.9820315

31.98203151-32.4558097

32.45580971-32.92958789

32.9295879-33.40336609

Salinity

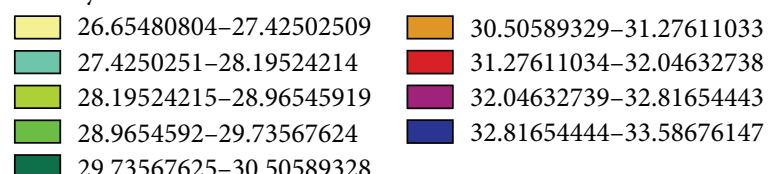

(b)

FIGURE 5: Average SAL distribution in winter 2013 (a) and 2002-2012 (b).

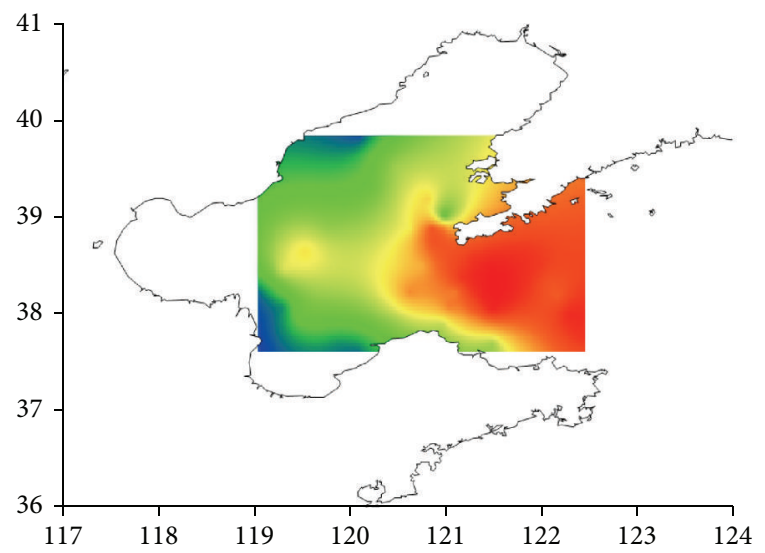

(a)
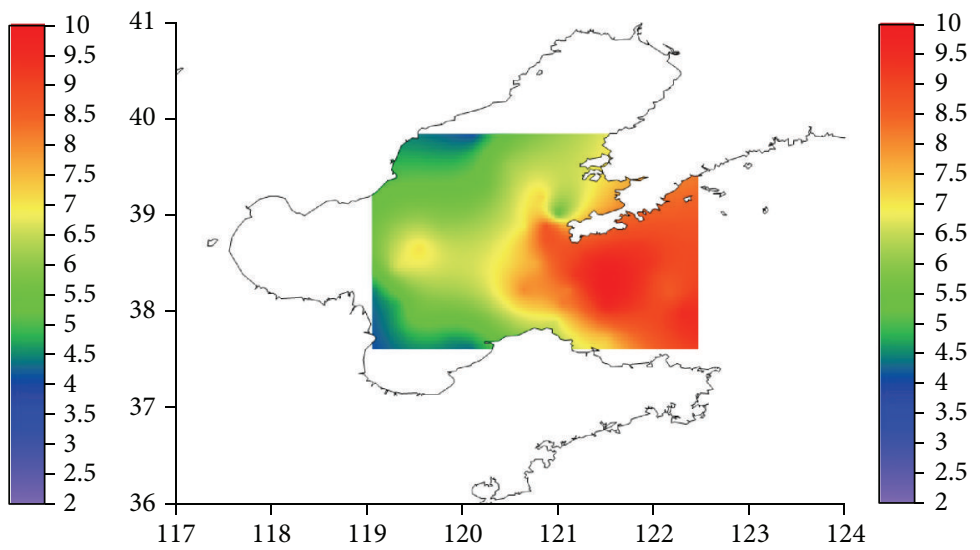

(b)

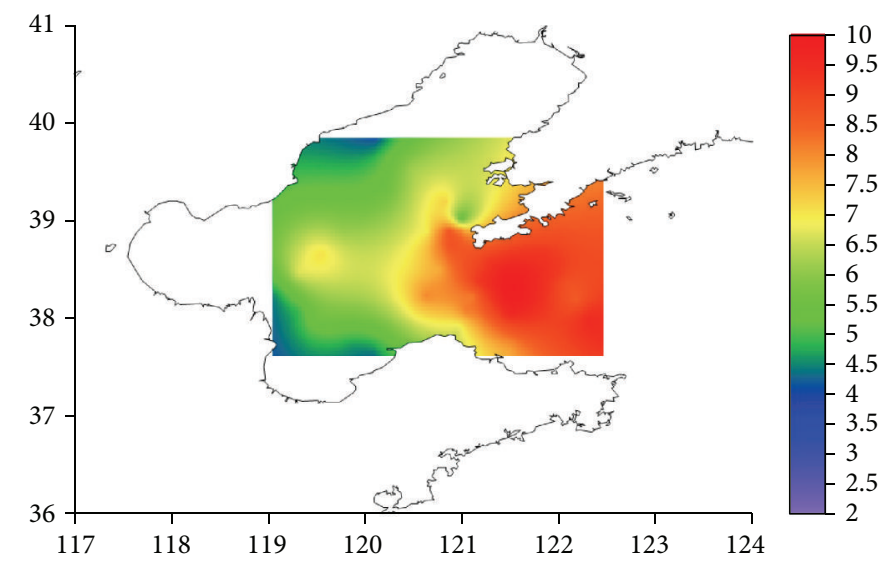

(c)

FIgURE 6: The SST data from 42 cross section stations in Y-B on December 17-24, 2013: (a) sea surface; (b) 10 m; (c) sea bottom (unit: ${ }^{\circ}$ C). 


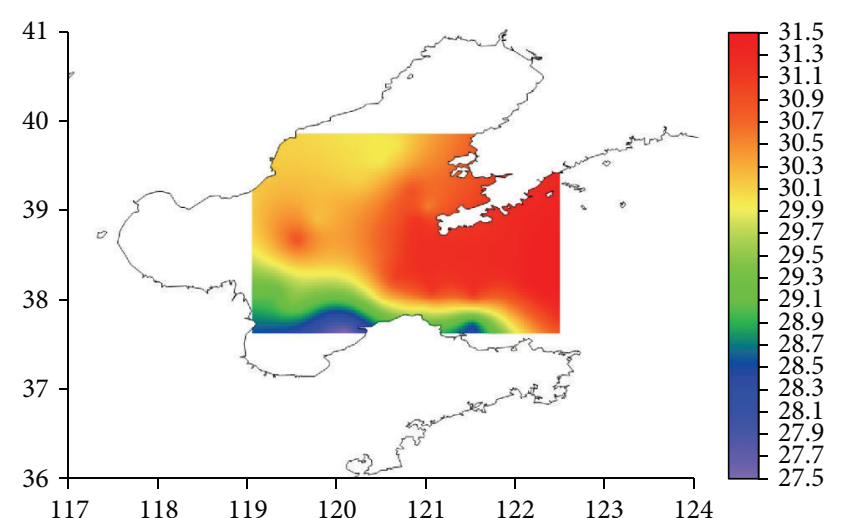

(a)

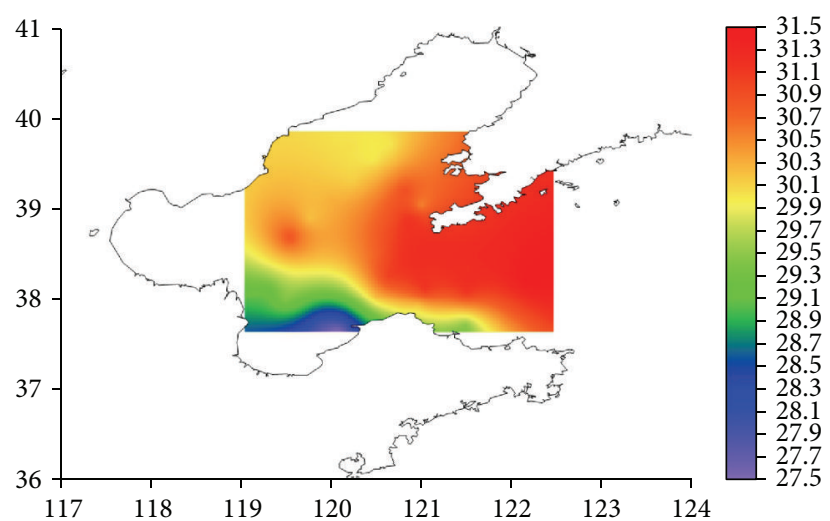

(b)

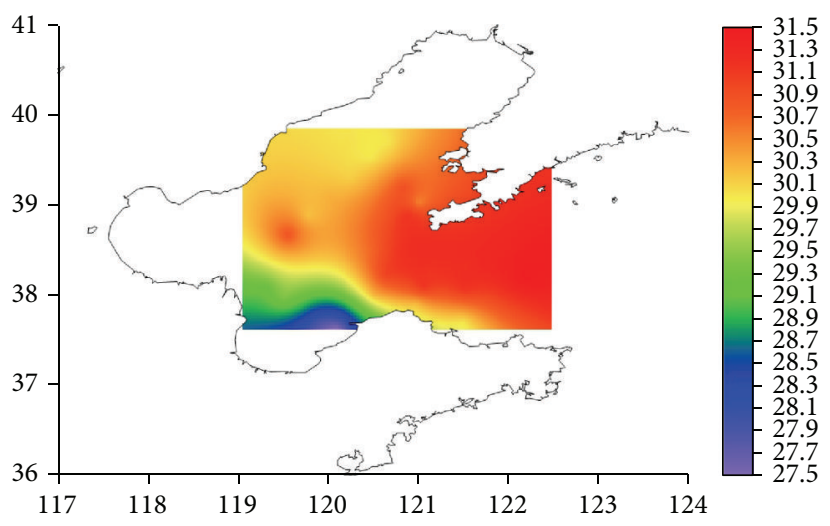

(c)

Figure 7: The SAL data from 42 cross section stations in Y-B on December 17-24, 2013: (a) sea surface; (b) 10 m; (c) sea bottom (unit: psu).

TABLE 3: Characteristics of the Y-B mixed zone in winter of 2002-2013.

\begin{tabular}{|c|c|c|c|c|c|c|c|c|}
\hline Year & Winter days & Northerly wind days & High wind days & $\operatorname{SST}\left({ }^{\circ} \mathrm{C}\right)$ & SAL (psu) & $\mathrm{CHL}\left(\mathrm{mg} / \mathrm{m}^{3}\right)$ & $V(\mathrm{~m} / \mathrm{s})$ & $V_{\text {dir }}\left({ }^{\circ}\right)$ \\
\hline 2002 & 89 & 68 & 29 & 6.16 & 31.51 & 2.44 & 7.49 & 159.01 \\
\hline 2003 & 90 & 64 & 32 & 7.22 & 31.4 & 3.23 & 7.66 & 130.02 \\
\hline 2004 & 89 & 67 & 32 & 7.71 & 31.46 & 2.79 & 8.18 & 163.20 \\
\hline 2005 & 89 & 70 & 31 & 6.29 & 31.61 & 3.34 & 7.8 & 163.05 \\
\hline 2006 & 90 & 64 & 23 & 7.81 & 31.3 & 2.66 & 6.82 & 152.35 \\
\hline 2007 & 86 & 59 & 19 & 7.32 & 31.68 & 3.1 & 8.01 & 245.32 \\
\hline 2008 & 87 & 53 & 26 & 7.03 & 31.35 & 3.63 & 7.97 & 213.69 \\
\hline 2009 & 86 & 56 & 28 & 5.59 & 31.17 & 2.31 & 7.76 & 221.77 \\
\hline 2010 & 88 & 55 & 34 & 6.15 & 30.98 & 3.49 & 8.3 & 230.12 \\
\hline 2011 & 90 & 62 & 24 & 7.01 & 31.34 & 3.33 & 7.48 & 242.85 \\
\hline 2012 & 90 & 53 & 18 & 5.51 & 31.19 & 3.3 & 7.30 & 215.06 \\
\hline 2013 & 90 & 53 & 6 & 7.23 & 31.43 & 3.02 & 7.83 & 208.37 \\
\hline
\end{tabular}

3.5. The In Situ and Cross Section Observation Data Analysis in Winter 2013. We analyzed the in situ and cross section observational SST and SAL data measured by shipboard CTD collected at the 42 stations shown in Figure 1 (+ symbol display site). These observations were made in Y-B on December 1724,2013 , at depths of $0 \mathrm{~m}$ and $10 \mathrm{~m}$ and at the bottom (Figures 6 and 7).

As shown in Figure 6, the SST data came from the sea surface (Figure 6(a)), from $10 \mathrm{~m}$ water depth (Figure 6(b)), and at the bottom (Figure 6(c)). The SAL data came from the sea surface (Figure 7(a)), $10 \mathrm{~m}$ water depth (Figure 7(b)), and the bottom (Figure $7(\mathrm{c})$ ).

3.6. Results. Through the aforementioned remote sensing inversion average data for years contrast, we found that, in winter 2013, winds were mostly northerly (Table 2 ). The average wind speeds of the two periods were similar, only $0.12 \mathrm{~m} / \mathrm{s}$ higher in 2013 than in 2002-2012, with an RMSE of 


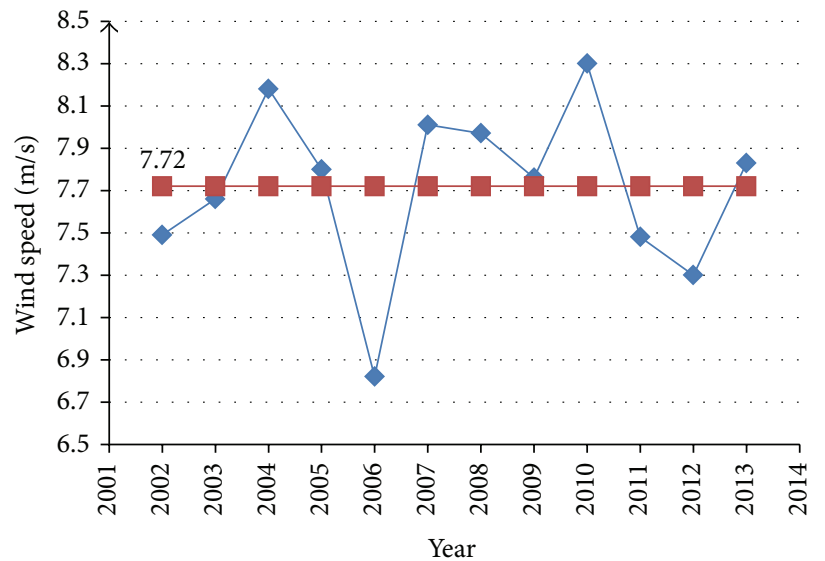

(a)

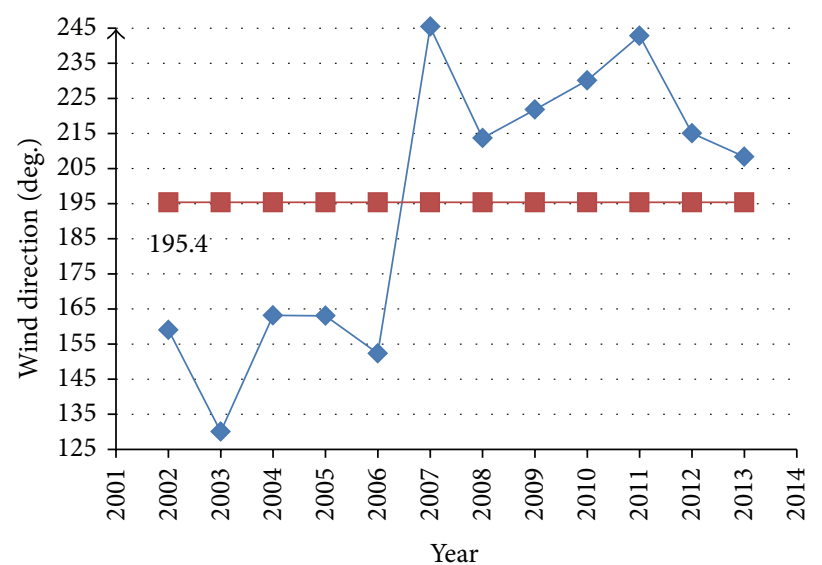

(b)

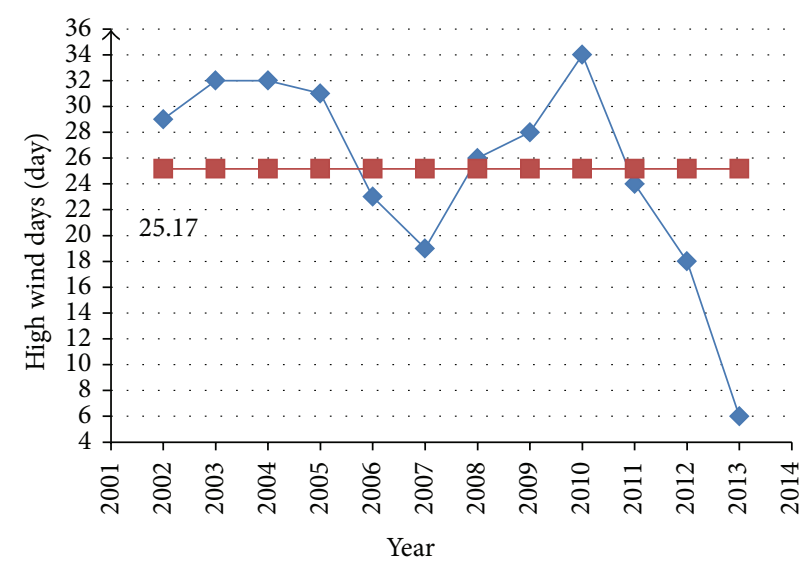

(c)

FIgURE 8: Average wind field parameters in winter between 2002 and 2013. (a) $V$ : wind speed; (b) $V_{\text {dir }}$ : wind direction; (c) high wind days.

$0.26 \mathrm{~m} / \mathrm{s}$. On average high wind days were 2 days shorter in winter 2013 compared with 2002-2012, which had an average of 8.97 days. However, the average SST was $0.52^{\circ} \mathrm{C}$ in 2013 , which was much higher than the average of 2002-2012; the RMSE was $1.85^{\circ} \mathrm{C}$. The average CHL in the mixed zone in winter 2013 was similar to the average from 2002 to 2012, only $0.04 \mathrm{mg} / \mathrm{m}^{3}$ lower in 2013 than in 2002-2012; the RMSE was $0.59 \mathrm{mg} / \mathrm{m}^{3}$. Figure 4 shows a low average CHL at $0-2 \mathrm{mg} / \mathrm{m}^{3}$ near the mixing zone in winter 2013, which is not existent in the previous decade to see Figure 4(b). The average SAL in winter 2013 was 32.01 and 31.29 psu in 2002-2012 (see Figure 5); RMSE was 1.84 psu. Thus, we hypothesized that the YSWC entered the Bohai Sea in winter 2013.

From in situ and cross section observational data, we found that a warm water mass (SST: $7-10^{\circ} \mathrm{C}$; SAL: $30.1-$ $31.5 \mathrm{psu}$ ) invaded the Bohai Sea from the Yellow Sea on December 17-24, 2013, at all depths. We found that, in December 2013, the SAL and SST from observational data did not vary greatly between different depths. Because of the shallowness of the research area and the wind and wave mixing in winter, the region formed a homogeneous mixed layer across different depths of seawater in Y-B, which confirms the winter 2013 remote sensing analysis. The YSWC invaded the Bohai Sea in winter 2013.
3.7. Discussion. To enable an understanding of the movement of the YSWC into the Bohai Sea, it is important to establish decision criteria by remote sensing data.

The YSWC is characterized by high temperature, high SAL, and low dissolved oxygen content. Figures 8(a), 8(b), 8(c), 9(a), 9(b), and 9(c) show that the average $V$, average $V_{\text {dir }}$, average high wind days, average SST, average SAL, and average CHL over 12 winters were $7.72 \mathrm{~m} / \mathrm{s}, 195.4^{\circ}, 25.17$ days, $6.76^{\circ} \mathrm{C}, 31.37 \mathrm{psu}$, and $3.05 \mathrm{mg} / \mathrm{m}^{3}$, respectively. Table 3 shows that northerly winds dominated in the mixed zone $\mathrm{Y}-\mathrm{B}$ in the winters of 2002-2013. There are no laws to follow from the average high wind days.

We found that the average $V$, average SST, and average SAL in winter 2013, retrieved by remote sensing data, were higher than the 12-year average. High wind days and average CHL were lower than the 12-year average (Table 4). The northerly winds dominated in winter 2013. By combining in situ, cross section observation and remote sensing data analysis, we found that the movement of the YSWC into the Bohai Sea is caused by positive anomalies of northerly wind speeds, SST, and SAL and a negative anomaly of CHL over multiyear average in the mixed zone Y-B.

According to the above criteria, the average SST in winter did not conform to the conditions in 2002, 2005, 2008, 2009, 


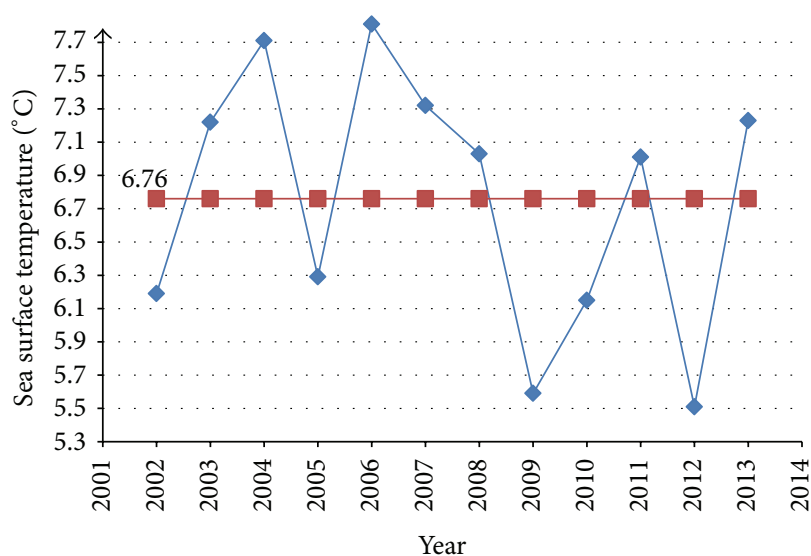

(a)

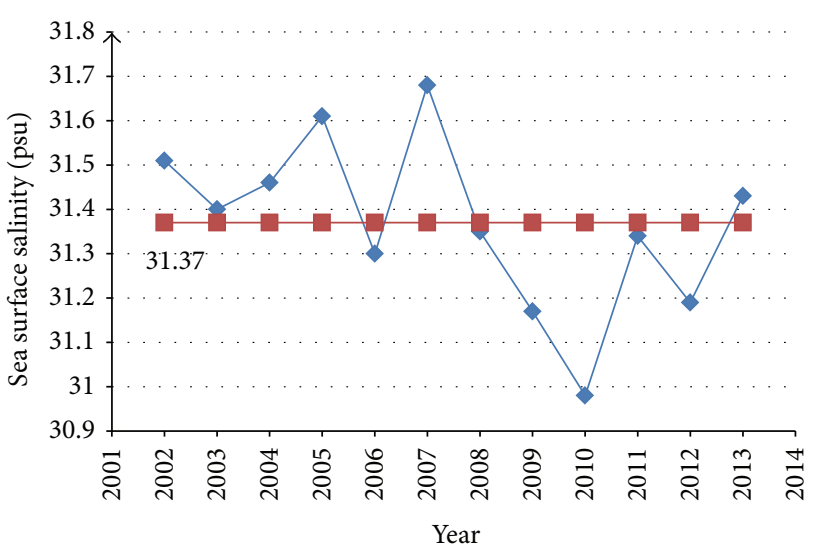

(b)

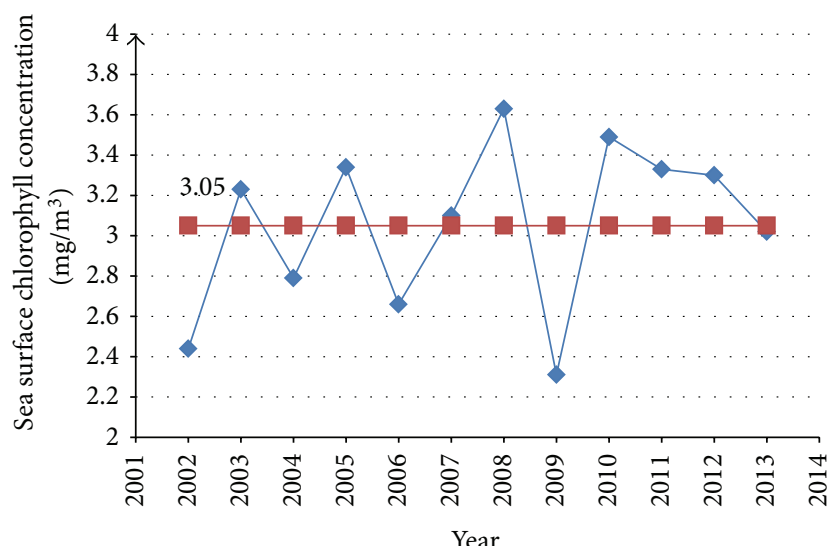

(c)

Figure 9: Average SST, SAL, and CHL in winter between 2002 and 2013. (a) Average SST; (b) average SAL; (c) average CHL.

TABLE 4: Analysis of characteristics of the movement of the YSWC into the Bohai Sea.

\begin{tabular}{|c|c|c|c|c|c|}
\hline Year & $\mathrm{SST}>6.76^{\circ} \mathrm{C}$ & $\mathrm{SAL}>31.37 \mathrm{psu}$ & $\mathrm{CHL}<3.05 \mathrm{mg} / \mathrm{m}^{3}$ & $V>7.72 \mathrm{~m} / \mathrm{s}$ & High wind days (day) \\
\hline 2002 & & $\checkmark$ & $\checkmark$ & & \\
\hline 2003 & $\checkmark$ & $\checkmark$ & & & \\
\hline 2004 & $\checkmark$ & $\checkmark$ & $\checkmark$ & $\checkmark$ & 32 \\
\hline 2005 & & $\checkmark$ & & $\checkmark$ & \\
\hline 2006 & $\checkmark$ & & $\checkmark$ & & \\
\hline 2007 & $\checkmark$ & $\checkmark$ & Nearby (3.1) & $\checkmark$ & 19 \\
\hline 2008 & & $\checkmark$ & & $\checkmark$ & \\
\hline 2009 & & & $\checkmark$ & $\checkmark$ & \\
\hline 2010 & & & & $\checkmark$ & \\
\hline 2011 & $\checkmark$ & & & & \\
\hline \multicolumn{6}{|l|}{2012} \\
\hline 2013 & $\checkmark$ & $\checkmark$ & $\checkmark$ & $\checkmark$ & 6 \\
\hline
\end{tabular}

2010, and 2012. The average SAL in winter did not conform to the conditions in 2006, 2009, 2010, 2011, and 2012. The average CHL in winter did not conform to the conditions in 2003, 2005, 2008, 2010, 2011, and 2012. The average wind speed in winter did not conform to conditions in 2002, 2003, 2006, 2011, and 2012 (see Tables 3 and 4).

\section{Conclusions}

In winters of 2004, 2007, and 2013, when northerly winds dominated, the average wind speeds were $8.18 \mathrm{~m} / \mathrm{s}, 8.01 \mathrm{~m} / \mathrm{s}$, and $7.83 \mathrm{~m} / \mathrm{s}$, respectively, which were all greater than the 12 year average $(7.72 \mathrm{~m} / \mathrm{s})$; the SAL and SST were higher than 
the 12 -year average $\left(6.76^{\circ} \mathrm{C}\right.$ and $\left.31.37 \mathrm{psu}\right)$, while the $\mathrm{CHL}$ was less than the 12 -year average $\left(3.05 \mathrm{mg} / \mathrm{m}^{3}\right.$, the average CHL is close to this value in winter 2007). The YSWC intrusion happened in 2007, 2004, and 2013, ranked by the intrusion strength. This conclusion was validated by the in situ and cross section observational data from winter 2013. We conclude that the YSWC intrusion into the Bohai Sea occurred when the wind speed, sea surface temperature, and SAL were above (or close to) the multiyear average and the $\mathrm{CHL}$ was less than (or close to) the multiyear average. This finding agrees with the model simulation results published in the literature $[4,7,8,17]$.

The study area is fully mixed in the winter owing to the wind field and ocean currents, and thus it is the ideal season to observe the intrusion of the YSWC into the Bohai Sea, by means of remote sensing; this conclusion is the same as Zhao et al. [17]. Therefore, the conclusions obtained from remote sensing data in this study are reasonable in this area, in the winter.

We also found that the YSWC intrusion into the Bohai Sea did not happen every year and was closely related to the wind field.

Future work shall increase in situ and cross section observational data from the study area and continue to verify the conclusions from remote sensing data. We will focus on the conditions and mechanism of the YSWC intrusion into the Bohai Sea during the autumn and winter and expand the study area to the north Yellow Sea and the Kuroshio area.

\section{Conflict of Interests}

The authors declare that there is no conflict of interests regarding the publication of this paper.

\section{Acknowledgments}

This project is financially supported by the "Strategic Priority Research Program" of the Chinese Academy of Sciences (no. XDA01020304) and by the National Natural Science Foundation of China (no. 41176160 and no. 4141101049). In addition, the authors thank ECMWF, EUMETSAT, KNMI, IFREMER/ CERSAT, GODIVA, NOAA, Météo-France, NDBC, O\&SI SAF, PMEL, and the UK Met Office for the courtesy of providing buoy, numerical, and satellite data used for daily ASCAT data production, evaluation, and validation. MODIS data were provided by NASA. Helpful advice from Dr. Xiaofeng Li NOAA is greatly appreciated.

\section{References}

[1] B. X. Gran, "The main biographic features of shallow water in the Yellow and East China Seas," Journal of Oceanography of Huanghai and Bohai Seas, vol. 3, no. 4, pp. 1-10, 1985.

[2] H. Titanium, "Beginning of the Kuroshio," in Kuroshio: Its Physical Aspects, H. Stommel and K. Yoshida, Eds., pp. 129-163, University of Tokyo Press, Tokyo, Japan, 1972.

[3] D. Song, X. Bao, X. Wang, L. Xu, X. Lin, and D. Wu, "The interannual variability of the Yellow Sea warm current surface axis and its influencing factors," Chinese Journal of Oceanology and Limnology, vol. 27, no. 3, pp. 607-613, 2009.

[4] X. Song, X. Lin, and Y. Wang, "The variability of the Yellow Sea warm current axis in winter and its possible reason," Periodical of Ocean University of China, vol. 39, supplement, pp. 259-266, 2009.

[5] G. Liu, W. Sun, K. Lei, and W. Jiang, "A numerical study of circulation in the Huanghai Sea and East China Sea: numerical simulation of barotropic circulation," Journal of Ocean University of Qingdao, vol. 32, no. 1, pp. 1-8, 2002.

[6] A. C. Mask, J. J. O’Brien, and R. Preller, "Wind-driven effects on the Yellow Sea warm current," Journal of Geophysical Research: Oceans, vol. 103, no. 13, Article ID 1998JC900007, pp. 3071330729, 1998.

[7] Y. Tang, E. Zou, and H. Lie, "On the origin and path of the Huanghai warm current during winter and early spring," Acta Oceanologica Sinica, vol. 23, no. 1, pp. 1-12, 2001.

[8] Y. Yuan, J. Su, and J. Zhao, "A single layer model of the continental shelf circulation in the East China Sea," Acta Oceanologica Sinica, vol. 4, no. 1, pp. 2-11, 1982.

[9] Y. Zhu and G. Fang, "Shelf and shallow water circulation of a three-dimensional barotropic model and its application in the Bohai Sea, Yellow sea and East China Sea," Acta Oceanologica Sinica, vol. 16, no. 6, pp. 11-26, 1994.

[10] J. B. Miu and X. Q. Liu, "The north Yellow sea and Bohai Sea in winter circulation dynamics numerical experiments," Acta Oceanologica Sinica, vol. 11, no. 1, pp. 15-22, 1989.

[11] H. Shen and H. Mao, "Basic hydrogeological characteristics of the Bohai Sea and the Yellow Sea of the western north," Bulletin of Marine Science, vol. 1, no. 1, pp. 1-22, 1964.

[12] J. Guo, X. Liu, and Q. Xie, "Characteristics of the Bohai Sea oil spill and its impact on the Bohai Sea ecosystem," Chinese Science Bulletin, vol. 58, no. 19, pp. 2276-2281, 2013.

[13] X. Li, C. Li, Q. Xu, and W. G. Pichel, "Sea surface manifestation of along-tidal-channel underwater ridges imaged by SAR," IEEE Transactions on Geoscience and Remote Sensing, vol. 47, no. 8, pp. 2467-2477, 2009.

[14] W. Shi, M. Wang, X. Li, and W. G. Pichel, "Ocean sand ridge signatures in the Bohai Sea observed by satellite ocean color and synthetic aperture radar measurements," Remote Sensing of Environment, vol. 115, no. 8, pp. 1926-1934, 2011.

[15] X. Li, W. Pichel, E. Maturi, P. Clemente-Colón, and J. Sapper, "Deriving the operational nonlinear multichannel sea surface temperature algorithm coefficients for NOAA-15 AVHRR/3," International Journal of Remote Sensing, vol. 22, no. 4, pp. 699704, 2001.

[16] X. Li, W. Pichel, P. Clemente-Colon, V. Kransnopolsky, and J. Sapper, "Validation of coastal sea and lake surface temperature measurements derived from NOAA/AVHRR data," International Journal of Remote Sensing, vol. 22, no. 7, pp. 1285-1303, 2001.

[17] S. Zhao, F. Yu, X. Y. Diao, and G. C. Si, “The path and mechanism of the Yellow Sea warm current," Marine Sciences, vol. 35, no. 11, pp. 73-80, 2011.

[18] D. L. Yuan, W. Q. Han, and D. X. Hu, "Surface Kuroshio path in the Luzon Strait area derived from satellite remote sensing data," Journal of Geophysical Research, vol. 111, no. C11, pp. 6379, 2006.

[19] L. R. Centurioni, P. P. Niiler, and D.-K. Lee, "Observations of inflow of Philippine sea surface water into the South China Sea through the Luzon strait," Journal of Physical Oceanography, vol. 34, no. 1, pp. 113-121, 2004. 
[20] A. Farris and M. Wimbush, "Wind-induced Kuroshio intrusion into the South China Sea," Journal of Oceanography, vol. 52, no. 6, pp. 771-784, 1996.

[21] J. Wang and C. S. Chern, "The warm-core eddy in the Northern South China Sea: I. Preliminary observations on the warm-core eddy," Acta Oceanographica Taiwanica, vol. 18, pp. 92-103, 1987.

[22] X. Yang, X. Li, Q. Zheng, X. Gu, W. G. Pichel, and Z. Li, "Comparison of ocean-surface winds retrieved from quikscat scatterometer and radarsat-1 SAR in offshore waters of the U.S. West Coast," IEEE Geoscience and Remote Sensing Letters, vol. 8, no. 1, pp. 163-167, 2011.

[23] X. Yang, X. Li, W. G. Pichel, and Z. Li, "Comparison of ocean surface winds from ENVISAT ASAR, MetOp ASCAT scatterometer, buoy measurements, and NOGAPS model," IEEE Transactions on Geoscience and Remote Sensing, vol. 49, no. 12, pp. 4743-4750, 2011.

[24] S. Qing, J. Zhang, T. Cui, and Y. Bao, "Retrieval of sea surface salinity with MERIS and MODIS data in the Bohai Sea," Remote Sensing of Environment, vol. 136, pp. 117-125, 2013.

[25] Y. Li, H. Chang, and Q. Wu, "Study of the characteristic and difference between sea and land wind of Bohai," Plateau Meteorology, vol. 32, no. 1, pp. 298-304, 2013. 

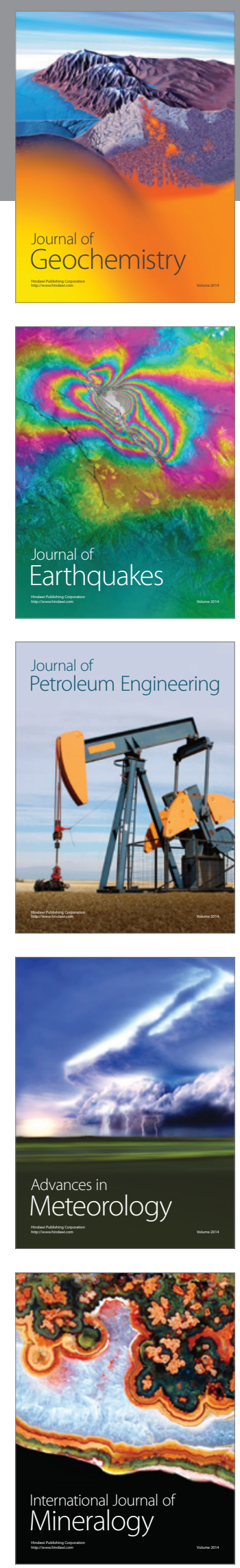
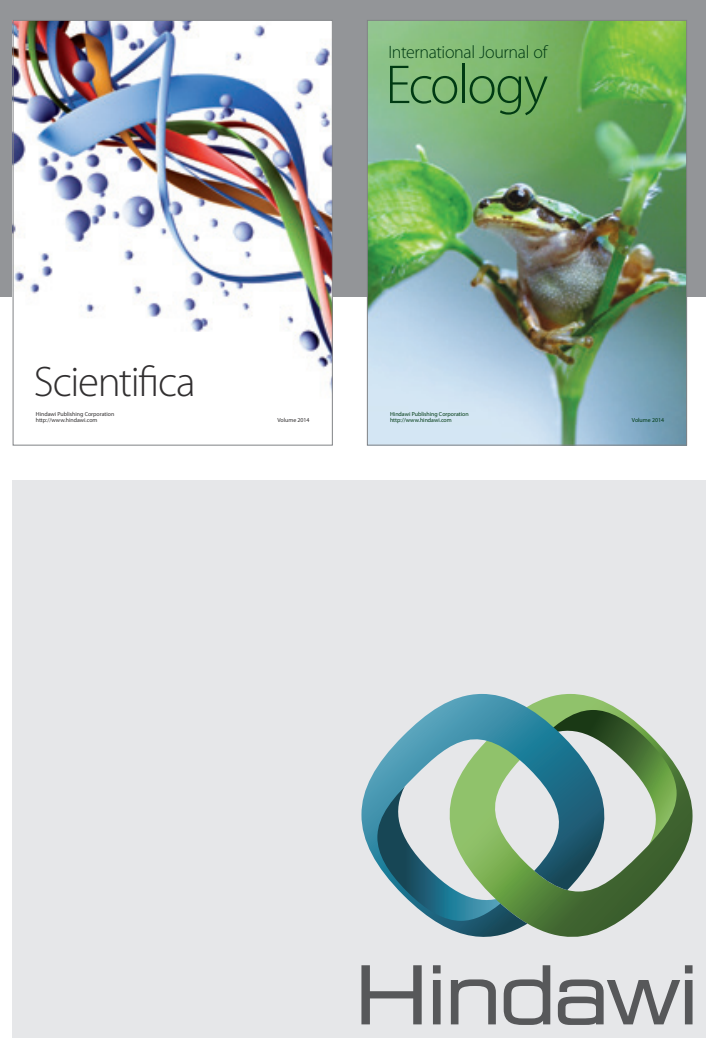

Submit your manuscripts at

http://www.hindawi.com
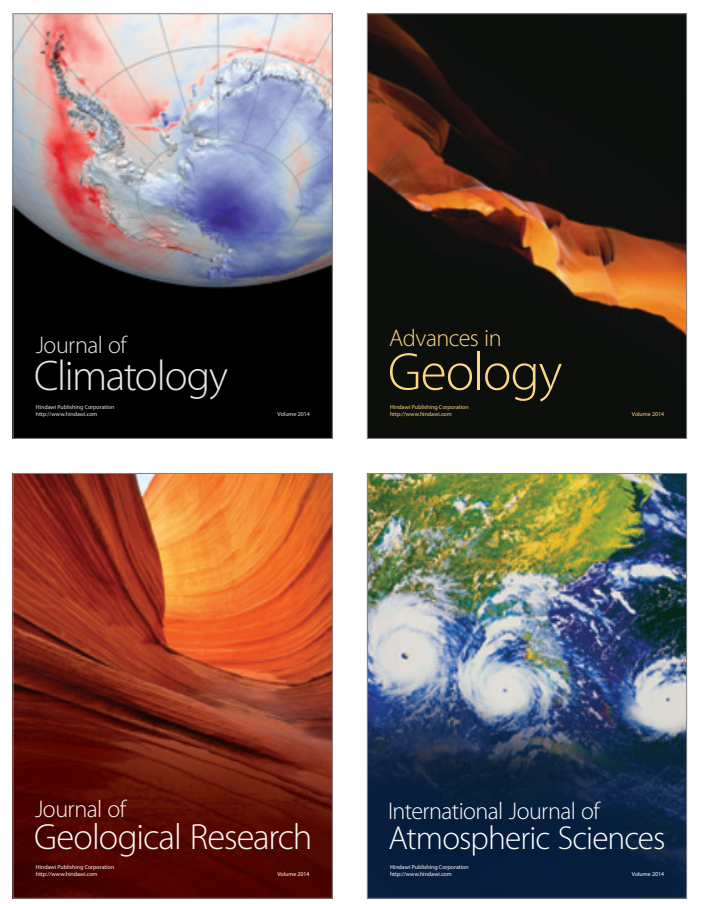

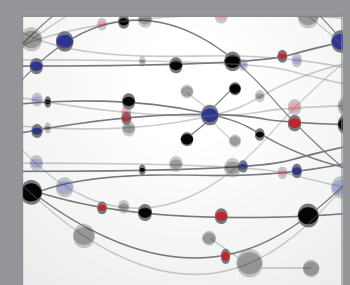

The Scientific

\section{World Journal}
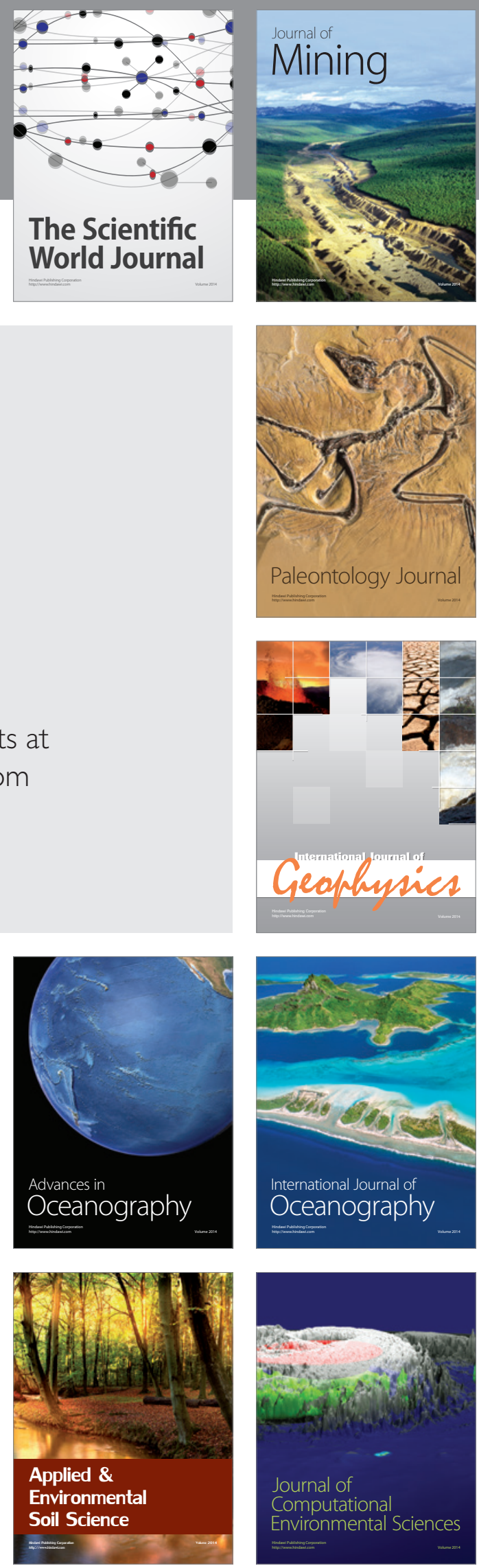